\section{ORIGINAL RESEARCH}

J.W. Lee

H.I. Shin

S.Y. Park

G.Y. Lee

H.S. Kang

\title{
Therapeutic Trial of Fluoroscopic Interlaminar Epidural Steroid Injection for Axial Low Back Pain: Effectiveness and Outcome Predictors
}

\begin{abstract}
BACKGROUND AND PURPOSE: An ESI for managing LBP is one of the most commonly performed interventions. The purpose of this observational study was to assess the effect of a therapeutic trial of a fluoroscopic interlaminar ESI for axial LBP and to analyze the outcome predictors.
\end{abstract}

\begin{abstract}
MATERIALS AND METHODS: All patients who received an interlaminar ESI for axial LBP at our facility in 2007 and 2008 were included. Initial short-term follow-up was done at $<1$ month after ESI. ESI was considered effective if patients had a reduction of $>50 \%$ in their pain scores. In July 2009 , telephone interviews were conducted by using formatted questions including the NASS patient-satisfaction index. The symptom-free interval was computed by the Kaplan-Meier method. Outcome predictors such as age, sex, duration of LBP, and MR imaging findings were statistically analyzed by the Mann-Whitney $U$ and the Fisher exact tests.
\end{abstract}

RESULTS: Eighty-one patients (male/female $=16: 65$; mean age, 49.9 years; range, 17-77 years) were included in the study. The interlaminar ESI was effective in 63 of the 81 patients $(77.8 \%)$ at initial short-term follow-up. For the 63 patients in whom ESI was effective, the median symptom-free interval was 154 days ( $95 \% \mathrm{Cl}, 96-212$ days). Among 68 patients for whom telephone interviews were possible, 44 patients $(64.7 \%)$ replied positively to the NASS patient satisfaction index (NASS patientsatisfaction index, 1 or 2). There were no significant outcome predictors.

CONCLUSIONS: The therapeutic trial of a fluoroscopic interlaminar ESI was effective for axial LBP without significant outcome predictors.

\begin{abstract}
ABBREVIATIONS: $\mathrm{CI}=$ confidence interval; $\mathrm{ESI}=$ epidural steroid injection; HIVD = herniated intervertebral disk; HIZ = high-intensity zone; LBP = low back pain; NASS = North American Spine Society; $\mathrm{Q}=$ question
\end{abstract}

$\mathbf{A}^{n}$ ESI for managing LBP is one of the most commonly performed interventions in the United States. ${ }^{1,2}$ Friedly et $\mathrm{al}^{3}$ reported administration of epidural injections in $36 \%$ of patients with axial LBP. However, there is no clinical evidence for the use of ESI in axial LBP except for 1 observational study that used the interlaminar approach ${ }^{4}$ and 1 randomized study $^{2}$ and 2 observational studies that used the caudal approach. ${ }^{5,6}$ Intervertebral disks can be a source of LBP without nerve root compression. ${ }^{7-9}$ The possible mechanism of diskogenic LBP is inflammatory change around the intervertebral disk. ${ }^{8,10}$ Many studies have shown that the nuclear material possesses the ability to irritate the nerve root by inducing inflammation. ${ }^{10-13}$ Because steroids have been presumed to have an anti-inflammatory action, it is natural to think that an anti-inflammatory agent would work when pain is thought to result from inflammation.

For the past several years, in the radiology department of our hospital, we have tried the interlaminar ESI procedure under fluoroscopic guidance for patients having axial LBP. Until now, a rehabilitation physician in our hospital has re-

Received March 8, 2010; accepted after revision April 20

From the Departments of Radiology (J.W.L., S.Y.P., G.Y.L., H.S.K.) and Rehabilitation Medicine (H.I.S.), Seoul National University Bundang Hospital, Gyeongi-Do, Korea.

Please address correspondence to Hyung Ik Shin, MD, Department of Rehabilitation Medicine, Seoul National University Bundang Hospital, 300 Gumidong, Bundag-Gu, Seong Nam, Gyeongi-Do, 463-707 Korea; e-mail: hyungik1@snu.ac.kr

Indicates article with supplemental on-line tables.

DOI 10.3174/ajnr.A2180 ferred all patients who were thought to be experiencing axial LBP and showed no improvement with previous medication and physical therapy to the radiology department for a therapeutic trial of an interlaminar ESI.

The purpose of this observational study was to assess the effect of the therapeutic trial of a fluoroscopic interlaminar ESI for axial LBP and to analyze the outcome predictors.

\section{Materials and Methods}

\section{Patient Selection}

This study was approved by the institutional review board, and informed consent was obtained. Three selection criteria for considering interlaminar ESI were the following: 1) axial LBP clinically determined by criteria given below, 2) absence of nerve root compression demonstrated by CT or MR imaging, and 3) no improvement with previous medication and physical therapy for $>2$ weeks. Axial LBP was clinically diagnosed by a rehabilitation physician using the following 5 criteria: 1) LBP without trauma history, 2) LBP without limb pain or radiating symptoms, 3) negative straight leg raising test, 4) no weakness or hypesthesia, and 5) a positive paraspinal compression maneuver as described below (Fig 1).

\section{Paraspinal Compression Maneuver}

The paraspinal compression maneuver was designed by a rehabilitation physician at our hospital (Fig 1).

Patient Position. The patient is in the prone position. A pillow is placed under the abdomen, producing a mild arching of the lower spine to relax the lumbosacral paraspinal muscle. For further relax- 


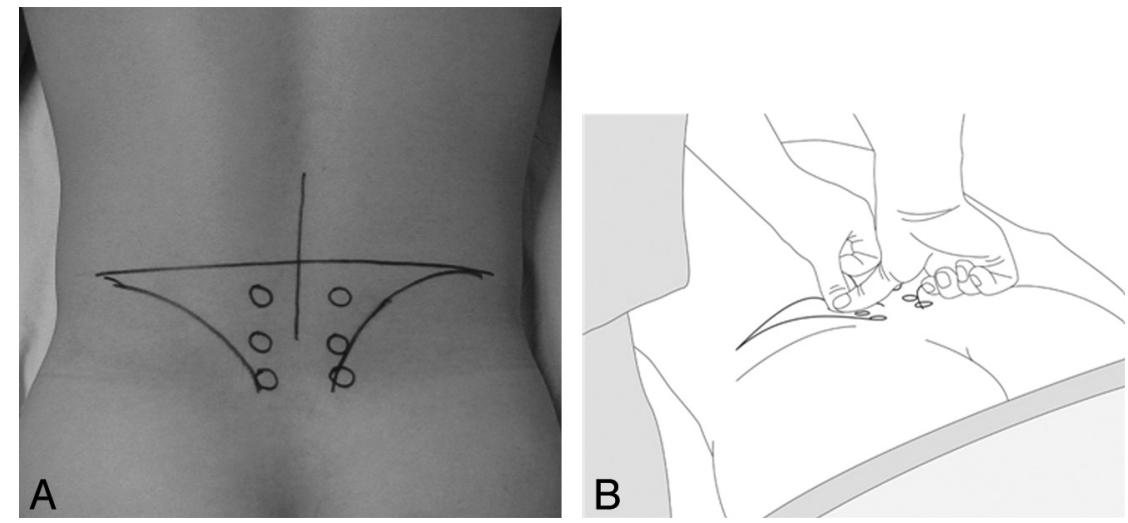

Fig 1. Paraspinal compression maneuver. An imaginary line is drawn horizontally between the tops of the iliac crests. The intersection point where the midline passes through the imaginary line vertically is marked. A total of 6 spots are marked. The first 2 spots are placed 2 finger widths laterally and 1 finger width below the intersect point. The second 2 spots are placed 1 finger width below the first spots. $A$, The third set of 2 spots is placed 1 finger width below the second spots. $B$, The examiner presses each spot with both thumbs. A positive sign of this maneuver is a definite sharp pain on 1 side and no pain on the other side.

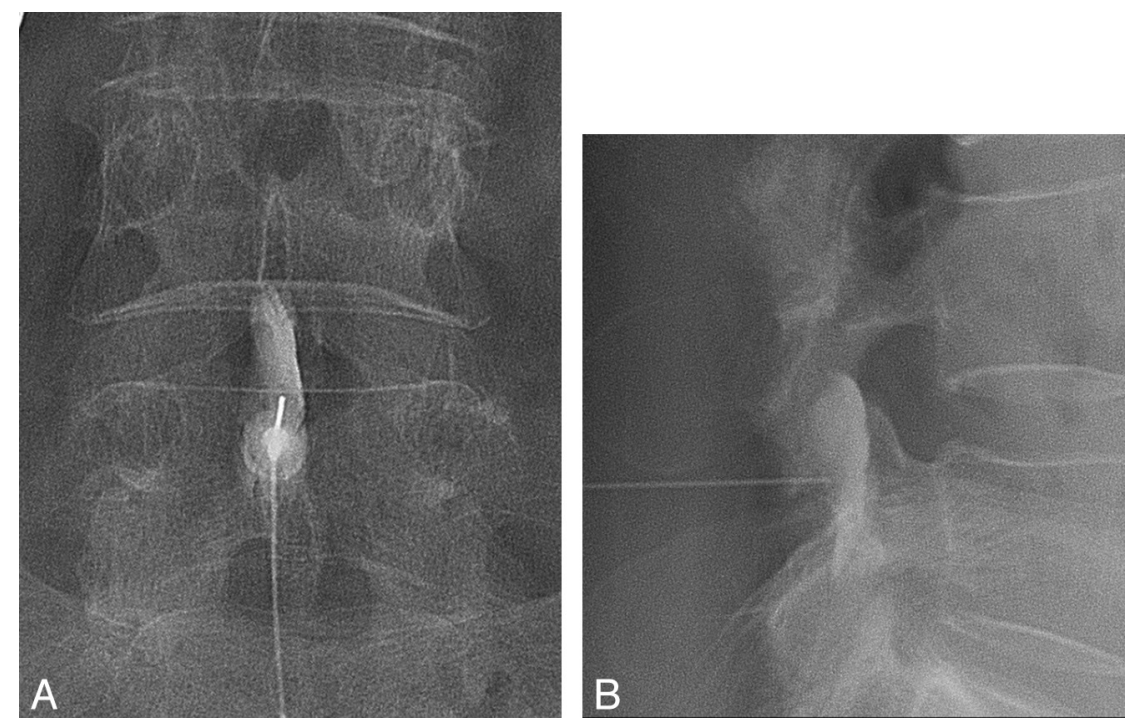

Fig 2. A 70-year-old woman received an interlaminar ESI. A 22-ga spinal needle was advanced into the posterior epidural space through the interlaminar space with intermittent injection of contrast agent until the contrast agent smoothly spread into the lumbar epidural space on anterior-posterior view $(A)$ and lateral view $(B)$. Then, a mixture of triamcinolone acetonide (Tamceton) and bupivacaine hydrochloride (Marcaine Spinal 0.5\% Heavy) was injected into the epidural space.

ation, the patient is asked to either push with the knees on the examining table or slightly elevate the pelvis off the table.

Maneuver. An imaginary line is drawn horizontally between the tops of the iliac crests. The intersection point where the midline passes through the imaginary line vertically is marked (Fig $1 A$ ). A total of 6 spots are marked. The first 2 spots are placed 2 finger widths laterally and 1 finger width below the intersect point. The second 2 spots are placed 1 finger width below the first spots. The third 2 spots are placed 1 finger width below the second spots. The examiner presses each spot with both thumbs (Fig 1B). A positive sign for this maneuver is a definite sharp pain on 1 side and not on the other side.

\section{Inclusion/Exclusion Criteria}

Inclusion criteria for this study were the following: 1) patients receiving interlaminar ESIs for axial LBP with the above selection criteria from January 2007 to December 2008, 2) the availability of either MR images or CT scans, 3) the presence of initial short-term follow-up results $<1$ month after injection, and 4$)$ patients with a numeric rating score $(0-10)$ of $>5$. Exclusion criteria were the following: 1$)$ pre- vious lumbar operation; 2) patients under litigation or having a legal issue; 3) history of psychiatric disease such as depression; 4) nerve root compression demonstrated on MR imaging or CT, by either disk herniation or spinal stenosis; 5) absence of MR images or CT scans; 6) absence of initial short-term follow-up data; and 7) initial shortterm follow-up $>1$ month after interlaminar ESI.

\section{Interlaminar ESI}

A lumbar interlaminar ESI was performed under fluoroscopic guidance. The level of injection was mostly L4 -5 , but L3-4 or L5-S1 was also chosen according to the level of abnormal disk or accessibility during the procedure. For multiple levels of disk disease, L4-5 was usually targeted first because most patients had LBP around L $4-5$ on physical examination. However, this could be changed according to the accessibility. All interlaminar ESI procedures were performed by 1 of 3 radiologists who have experience with $>1000$ ESI procedures. The uniplanar digital subtraction angiography unit (Intergris Allura Xper FD 20; Philips Healthcare, Best, the Netherlands) was used. With patients in the prone position and under sterile preparation, a 

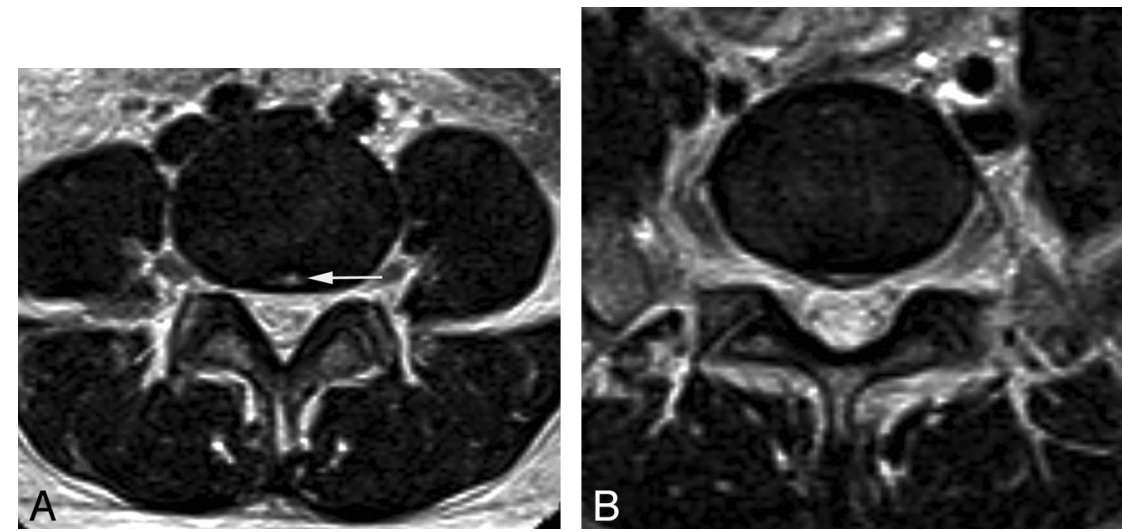

Fig 3. Annular tear and disk herniation at the central zone. MR image of a 33-year-old woman with LBP. A, On a T2 axial image at the L4-5 disk level, an annular tear at the central zone is seen as the focal high signal intensity in the central zone (arrow), the so-called "high-intensity zone," B, On a T2 axial image at the L5-S1 level, disk herniation at the central zone is noted.

22-ga spinal needle was advanced into the posterior epidural space through the interlaminar space with intermittent injection of contrast agent (Omnipaque 300 [iohexol, $300 \mathrm{mg}$ iodine per $\mathrm{mL}$ ]; Amersham Health, Princeton, New Jersey) until the contrast agent smoothly spread into the lumbar epidural space (Fig 2). Then, a mixture of $40 \mathrm{mg}$ triamcinolone acetonide suspension (40 mg per milliliter; Tamceton, Hanall Pharmaceutical, Seoul, Korea) and $1.5 \mathrm{~mL}$ of normal saline and a mixture of $1 \mathrm{~mL}$ of bupivacaine hydrochloride $(0.5$ $\mathrm{mL} / 0.5 \%$, Marcaine Spinal 0.5\% Heavy; AstraZeneca, Westborough, Massachusetts) and $0.5 \mathrm{~mL}$ of normal saline were injected into the epidural space. The steroid mixture was injected first, and the anesthetic mixture was injected sequentially.

\section{Initial Short-Term Follow-Up}

We did 1 interlaminar ESI for each patient without a series of injections. After injection, the patients were followed by the rehabilitation physician. Initial short-term follow-up was scheduled at 2 weeks. Patients' responses were determined by the rehabilitation physician as effective or not, depending on whether the patient reported a reduction of $>50 \%$ in his or her pain score after injection. Patients whose pain scores demonstrated the effectiveness of the procedure after ESI were prescribed core exercises. Patients were initially followed up for 2 weeks after interlaminar ESI and then for another 4 weeks by the rehabilitation physician. The rehabilitation physician advised the patients to return to our hospital immediately if symptoms recurred. If the patient's back pain recurred, the rehabilitation physician recorded the pain in the medical chart and referred the patient to the radiology department for a repeat ESI.

\section{Chart Review}

In June and July 2009, a retrospective chart review was conducted by a spine radiologist. The level of the initial interlaminar ESI was gathered by chart documentation. The patients' responses recorded on the medical charts were obtained. Initial short-term response, recurrence or not, recurrence date (if recurrence), and symptom-free last follow-up date (if no recurrence) were gathered on the basis of the medical charts. If the recurrence was not clearly demonstrated on the medical chart, a telephone interview was attempted. The duration of symptom relief was classified as follows: no relief, $<1$ month's relief, between 1 and 2 months' relief, $>2$ months' relief, $>6$ months' relief, and $>1$ year's relief according to the initial response and recurrence interval after the interlaminar ESI.

The total number of interlaminar ESI procedures that were re-

\begin{tabular}{lc}
\hline \multicolumn{1}{l}{ Table 1: Patient group according to duration of symptom relief } \\
\hline Group & No. Patients (\%) \\
\hline No relief & $17(21 \%)$ \\
$<1$ Month's relief & $19(23.5 \%)$ \\
$1-2$ Months' relief & $10(12.3 \%)$ \\
$2-6$ Months' relief & $5(6.2 \%)$ \\
$6-12$ Months' relief & $15(18.5 \%)$ \\
$>1$ Year's relief & $15(18.5 \%)$ \\
Total & $81(100 \%)$ \\
\hline
\end{tabular}

peated until July 2009 was also counted for the included patients. Information about age, sex, and duration of LBP ( $<1$ month, 1-3 months, 3-6 months, and $>6$ months) was gathered. A radiologist also checked for complications that required additional management or hospitalization after the interlaminar ESI.

\section{MR Imaging Analysis}

MR imaging was analyzed by 2 radiologists in consensus who were blind to the ESI effect. The radiologists focused on the morphologic change in the intervertebral disk and the adjacent marrow change. Disk herniation was defined according to the disk nomenclature system recommended by the combined task forces of the NASS, the American Society of Spine Radiology, and the American Society of Neuroradiology. ${ }^{14}$ Patients who had disk herniation with nerve root compression were excluded as described below. An annular tear was regarded as present if there was a high-intensity zone on the MR image. ${ }^{15}$ Patients with at least 1 level of annular tear or disk herniation at the central zone were also documented (Fig 3). The central zone was defined as between the edge of the medial facet according to the disk nomenclature. ${ }^{14}$ We also checked for an intervertebral disk herniation (Schmorl nodes) at the lumbar level. ${ }^{14}$ Adjacent marrow change was described according to Modic type 1, 2, and $3 .{ }^{16}$ Facet arthropathy was also evaluated and considered as present when there was 1 of following features on T2-weighted axial images: joint space obliteration, osteophytes, joint effusion, subchondral sclerosis, or subchondral cyst in the facet joint.

\section{Telephone Interview}

In July 2009, telephone interviews were conducted with formatted questions by 2 researchers under the supervision of a spine radiologist. The formatted questions are shown in On-line Table 1. Each patient was asked 7 questions, and the replies were recorded. The 4-point NASS patient-satisfaction index was also used to evaluate 
patients by telephone interview as follows: $1=$ the interlaminar ESI met my expectations; 2 = I improved less than I had hoped, but I would undergo the same procedure again for the same result; $3=$ the interlaminar ESI helped, but I would not undergo the same procedure again for the same result; and $4=\mathrm{I}$ am the same or worse than before an interlaminar ESI. ${ }^{17}$

\section{Statistical Analysis}

To find the median symptom-free interval after improvement due to an interlaminar ESI, we used the Kaplan-Meier method. "Symptomfree last follow-up date" or "recurrence date" was used for the statistical analysis of the symptom-free interval.

The relationship between the duration of LBP ( $<1$ month, 1-3 months, 3-6 months, and $>6$ months) and the initial response was evaluated by the $\chi^{2}$ test.

To evaluate the outcome predictors, we determined outcome in 2 ways. The patients were divided into 2 groups according to their initial response to the interlaminar ESI (effective or ineffective), and possible outcome predictors were evaluated for the 2 groups by statistical analysis as described below. The patients were also placed in 2 groups by using the following NASS patient-satisfaction index assessed by telephone interview in July 2009: positive satisfaction (NASS 1 or 2 ) or negative satisfaction (NASS 3 or 4). Possible outcome predictors were also statistically analyzed for the 2 groups as described below.

Age differences and the number of abnormal disk levels were evaluated by the Mann-Whitney $U$ test. Other possible outcome predictors such as sex and duration of LBP ( $<$ or $>3$ months) were evaluated by the Fisher exact test. The presence of at least 1 level of Modic type 1, the presence or absence of at least 1 level of disk herniation or annular tear at the central zone, the presence of at least 1 level of Schmorl nodes, and the presence of facet arthropathy were also evaluated as possible outcome predictors for both initial response and NASS patient satisfaction index by the Fisher exact test.

\section{Results}

\section{Patients}

In total, 81 patients (male/female $=16: 65$; mean age, $49.9 \pm$ 14.4 years; range, $17-77$ years) were included in this study. The duration of LBP was $<1$ month in 27 patients, $1-3$ months in 14 patients, $3-6$ months in 15 patients, and $>6$ months in 25 patients.

\section{Level of Interlaminar ESI}

An interlaminar ESI was performed in 4 patients via L3-4, in 67 patients via L4-5, and in 10 patients via L5-S1.

\section{MR Imaging Findings}

MR imaging was performed for 67 patients, and CT was performed for the remaining 14 patients. An annular tear or disk herniation at the central zone was noted in 50 of 67 patients (74.6\%). Schmorl nodes were seen in 8 of 67 patients. At least 1 level of any type of Modic change was seen in 10 of 67 (14.9\%) patients. At least 1 level of Modic type 1 change was seen in only 2 of 67 patients (2.5\%). At least 1 level of Modic type 2 change was seen in 7 of 67 patients (10.4\%). At least 1 level of Modic type 3 change was seen in 1 of 67 patients $(1.4 \%)$. Facet arthropathy was seen in 19 of 67 patients $(28.4 \%)$.

\begin{tabular}{|c|c|c|c|}
\hline & $\begin{array}{l}\text { Improvement } \\
(n=63)\end{array}$ & $\begin{array}{c}\text { No Improvement } \\
(n=18)\end{array}$ & $P$ Value \\
\hline$\overline{\text { Age }^{b}}$ & $50 \pm 13.5$ & $49.6 \pm 17.6$ & .914 \\
\hline \multicolumn{4}{|l|}{ Sex } \\
\hline Male & $10(62.5 \%)$ & $6(37.5 \%)$ & .175 \\
\hline Female & $53(81.5 \%)$ & $12(18.5 \%)$ & \\
\hline \multicolumn{4}{|l|}{ Duration of LBP } \\
\hline$<3$ Months & $32(78.0 \%)$ & $9(22.0 \%)$ & 1.000 \\
\hline$>3$ months & $31(77.5 \%)$ & $9(22.5 \%)$ & \\
\hline
\end{tabular}

a Data are number of patients.

${ }^{b}$ Mean age (years).

\section{Response after Interlaminar ESI}

Follow-up was performed at $13.4 \pm 7.7$ days on average (range, 7-31 days). An interlaminar ESI was effective in 63 of 81 patients $(77.8 \%)$ at the initial short-term follow-up. Recurrence was seen in 34 of those 63 patients (54\%). For the 63 patients in whom an ESI was effective, the median symptomfree interval was 154 days (95\% CI, 96-212 days). Patients were grouped according to their duration of symptom relief as shown in Table 1 . Thirty patients (37\%) reported $>6$ months' symptom relief. The total number of ESI procedures was 1 in 54 patients (66.6\%), 2 in 21 patients (25.9\%), 3 in 5 patients, and 4 in 1 patient. No patient required additional management or showed permanent damage due to complications after an interlaminar ESI.

LBP duration ( $<1$ month, $n=27,33.3 \%$; $1-3$ months, $n=14,17.3 \%$; $3-6$ months, $n=15,18.5 \%$; and $>6$ months, $n=25,30.9 \%)$ was not significantly related to the initial response $(P=.173)$. ESI was effective in 20 of 27 patients with an LBP duration of $<1$ month (74.1\%), in 12 of 14 patients with $1-3$ months $(85.7 \%)$, in 9 of 15 patients with 3-6 months $(60.0 \%)$, and in $22-25$ patients with $>6$ months $(88.0 \%)$.

\section{Telephone Interview}

Of the 81 patients, telephone interviews were possible with 68 (84\%). For the remaining 13 patients, telephone interviews were attempted but failed. The results are summarized in Online Tables 2-5. In addition, approximately two-thirds of patients replied that they wanted to repeat the interlaminar ESI in a similar attack of LBP (63.2\%) and wanted to recommend an ESI to others (67.6\%). About two-thirds of patients $(64.7 \%)$ replied they had experienced positive satisfaction (NASS patient-satisfaction index 1 or 2). Two patients replied that they had undergone an operation since the interlaminar ESI.

\section{Possible Outcome Predictors}

In terms of initial short-term response after an initial interlaminar ESI, there were no significant outcome predictors. These clinical outcome predictors are summarized in Table 2. Among 67 patients who had MR images, the number of abnormal disk levels on MR imaging was not significantly different between the effective $(2.34 \pm 1.19)$ and ineffective group $(2.07 \pm 1.07)(P=.714)$. Between the effective $(n=53)$ and ineffective group $(n=14)$, other MR imaging findings such as the presence of at least 1 level of disk herniation or annular tear at the central zone (40/53 versus 10/14), the presence of at 


\begin{tabular}{|c|c|c|c|}
\hline \multicolumn{4}{|c|}{$\begin{array}{l}\text { Table 3: Possible clinical outcome predictors for interlaminar ESI in } \\
\text { terms of the NASS patient-satisfaction index }{ }^{\mathrm{a}}\end{array}$} \\
\hline & $\begin{array}{l}\text { NASS } 1 \text { or } 2 \\
(n=44)\end{array}$ & $\begin{array}{l}\text { NASS } 3 \text { or } 4 \\
(n=24)\end{array}$ & $P$ Value \\
\hline $\mathrm{Age}^{\mathrm{b}}$ & $49.1 \pm 15.0$ & $50.8 \pm 12.3$ & .734 \\
\hline \multicolumn{4}{|l|}{ Sex } \\
\hline Male & $6(46.2 \%)$ & $7(53.8 \%)$ & .195 \\
\hline Female & $38(69.1 \%)$ & $17(30.9 \%)$ & \\
\hline \multicolumn{4}{|l|}{ Duration of LBP } \\
\hline$<3$ Months & $22(62.9 \%)$ & $13(37.1 \%)$ & .803 \\
\hline$>3$ Months & $22(66.7 \%)$ & $11(45.8 \%)$ & \\
\hline \multicolumn{4}{|c|}{$\begin{array}{l}\text { a Data are number of patients. The NASS patient-satisfaction index was obtained in } 66 \\
\text { patients. } \\
\text { b Mean age (years). }\end{array}$} \\
\hline \multicolumn{4}{|c|}{$\begin{array}{l}\text { Table 4: Possible MR imaging outcome predictors for interlaminar } \\
\text { ESI in terms of the NASS patient-satisfaction scale }{ }^{\mathbf{a}}\end{array}$} \\
\hline & $\begin{array}{l}\text { NASS } 1 \text { or } 2 \\
(n=37)\end{array}$ & $\begin{array}{l}\text { NASS } 3 \text { or } 4 \\
(n=19)\end{array}$ & $P$ Value \\
\hline \multicolumn{4}{|c|}{ Central HIZ or HIVD } \\
\hline Present & $28(66.7 \%)$ & $14(33.3 \%)$ & 1.000 \\
\hline Absent & $9(64.3 \%)$ & $5(35.7 \%)$ & \\
\hline \multicolumn{4}{|l|}{ Schmorl nodes } \\
\hline Present & $5(71.4 \%)$ & $2(28.6 \%)$ & 1.000 \\
\hline Absent & $32(65.3 \%)$ & $17(34.7 \%)$ & \\
\hline \multicolumn{4}{|l|}{ Modic type 1} \\
\hline Present & $1(50 \%)$ & $1(50 \%)$ & 1.000 \\
\hline Absent & $36(66.7 \%)$ & $18(33.3 \%)$ & \\
\hline \multicolumn{4}{|c|}{ Facet arthropathy } \\
\hline Present & $9(24.3 \%)$ & $7(36.8 \%)$ & .362 \\
\hline Absent & $28(75.7 \%)$ & $12(63.2 \%)$ & \\
\hline
\end{tabular}

a Data are number of patients. Both the NASS patient-satisfaction index and MR imaging were available in 56 patients.

least 1 level of the Schmorl nodes (7/53 versus 1/14), the presence of at least 1 level of Modic type 1 (2/53 versus 0/14), and the presence of facet arthropathy (15/53 versus 4/14) were also not statistically significant. In terms of the NASS patientsatisfaction index, there was also no significant outcome predictor. These results are summarized in Tables 3 and 4.

\section{Discussion}

This study showed the following results: 1) interlaminar ESI was effective for axial LBP in four-fifths of patients $(77.8 \%)$ without significant outcome predictors, 2) recurrence was noted in half of the patients in whom ESI was effective (54\%) with an approximate 5-month symptom-free interval (median, 154 days; 95\% CI, 96-212 days), and 3) approximately two-thirds of patients $(64.7 \%)$ replied, in a later telephone interview, that they had positive satisfaction and said they were willing to repeat the procedure.

Modern technology, including MR imaging, CT, neurophysiologic testing, and comprehensive physical examination with psychological evaluation, can identify the cause of LBP in only $15 \%$ of patients in the absence of disk herniation and neurologic deficit. ${ }^{7}$ In a study by Manchikanti et al ${ }^{18}$ of the relative contributions of various structures in patients with chronic LBP without evidence of disk protrusion or radiculopathy, $40 \%$ of the patients were shown to have facet joint pain; 26\%, diskogenic pain; 2\%, sacroiliac joint pain; possibly $13 \%$, segmental dural/nerve root pain; and 19\%, pain with no identification of cause. Consequently, approximately $58 \%$ of patients with either diskogenic pain, segmental dural nerve root pain, or nonidentifiable cause may respond to epidural injections.

According to a recently published systematic review of blind lumbar interlaminar ESI, the evidence is lacking for short- and long-term relief for diskogenic pain. ${ }^{7}$ To our knowledge, no randomized trials for interlaminar ESI to manage LBP without disk herniation have been conducted.

There was 1 observational study about spinal steroid injection for degenerative disk disease. ${ }^{4}$ Patients received either interlaminar or transforaminal ESIs, all of which were performed under fluoroscopy; however, the proportion of patients receiving interlaminar ESIs was not described. The authors concluded that patients may have short-term benefit from ESI without disk herniation or stenosis. This was similar to our results. However, Buttermann's study ${ }^{4}$ had an extensive dropout rate of $60 \%$ during 2 years. Ultimately, at 2 years, 49 of the 139 patients (35\%) had undergone a fusion. This result was different from ours because in our study, only 2 patients $(2.9 \%)$ underwent an operation and approximately two-thirds of patients $(64.7 \%)$ replied that they had experienced positive satisfaction and, in a later telephone interview, observed that they were willing to repeat the procedure.

In Buttermann's study, ${ }^{4}$ ESIs were performed in 93 patients with Modic type 1 endplate changes and in 139 patients without Modic type 1 endplate changes. ${ }^{4}$ According to that study, ESIs are more effective in patients with MR imaging findings of Modic type 1 endplate changes. ${ }^{4}$ This result was different from ours, which showed that the Modic type 1 endplate change was not as common in patients with axial LBP and was not an outcome predictor after ESI. The study population of Buttermann's study was somewhat different from ours because that study consisted of patients with degenerative disk disease with $>1$ year of chronic LBP, but our study consisted of patients with LBP at the acute or chronic stage.

The underlying mechanism of action of an epidurally administered steroid is believed to achieve the neural blockade by altering or interrupting the nociceptive input, reflex mechanism of the afferent fibers, self-sustaining activity of the neurons, and the pattern of central neuronal activities. Furthermore, corticosteroids have been shown to reduce inflammation by inhibiting either the synthesis or release of a number of proinflammatory mediators and by causing a reversible local anesthetic effect. ${ }^{2,19,20}$

The correct diagnosis and treatment of axial LBP are still challenging. Provocation diskography was known to be the best diagnostic method for diskogenic LBP, but there is a still debate about the role of provocation diskography for the diagnosis of diskogenic LBP. ${ }^{21-24}$ Due to the invasive manner and possible complications such as infection, provocation diskography is not easily considered. In addition, there is no standard treatment method for diskogenic LBP even after diagnosis by provocation diskography. An operation cannot guarantee symptom relief for diskogenic LBP diagnosed by provocation diskography. ${ }^{22}$ So, we did not perform provocation diskography for the patients having axial LBP routinely because it is more painful and invasive than an interlaminar ESI. Provocation diskography was reserved only for patients who considered an operation after a failed interlaminar ESI. We suggest that the therapeutic trial of an interlaminar ESI before provocation diskography for axial LBP is reasonable 
because an interlaminar ESI is thought be safer and less invasive than provocation diskography.

In this study, we used a paraspinal compression maneuver for diagnosis of axial LBP. We excluded the patients who showed bilateral pain provocation during this maneuver because bilateral pain provocation could be induced by the maneuver itself.

Multiple approaches available to access the epidural space in the lumbosacral spine include interlaminar, transforaminal, and caudal. Interlaminar ESI rather than caudal ESI was selected in our hospital because in our experience, the interlaminar approach is less painful than the caudal approach during injection. Although interlaminar epidural injection was targeted to the posterior epidural space, we thought that the drugs could spread into the ventral epidural space with a somewhat larger volume. Because injection of drugs into the posterior epidural space was less irritating, we were able to inject a larger volume by interlaminar epidural injection, which may enable the drug to spread easily into the ventral epidural space.

On the basis of our experience, interlaminar epidural injection has some advantages for axial LBP. First, during transforaminal epidural injections, part of the contrast agent leaks into the spinal nerve. In addition, during transforaminal epidural injection, contrast agents tend to spread into the ipsilateral portion of the epidural space, so bilateral transforaminal epidural injection should be considered for bilateral distribution. In comparison, during interlaminar ESI, most contrast agent had a bilateral distribution in the epidural space, which could cover more lumbar levels and the most epidural space with a single injection. Second, interlaminar epidural injections were usually less painful than transforaminal epidural injections and less invasive than intradiskal injection. For the therapeutic trial for axial LBP, we chose less painful and less invasive injection procedures.

The use of an ESI has been debated due to its poor longterm results for managing LBP. However, although the patients experienced periodic aggravation of LBP even after relief by an ESI, the ESI has a role because it can control severe LBP at each episode. According to our results, approximately two-thirds of patients are willing to repeat the ESI if the pain recurs. This means that the ESI was a good treatment option for patients when their LBP was severe. To avoid overuse of steroids, strict guidelines are necessary for the frequency or interval of ESIs. Following the guidelines of the American Society of Interventional Pain Physicians, an ESI was performed a maximum of 6 times per year in our department. ${ }^{25}$ LBP subsides with time in many patients. Therefore, the main role of the ESI was to relieve back pain sooner and help patients quickly return to normal activities. Because exercise is very important for managing LBP but difficult for patients experiencing pain, ESI also has a role in relieving severe pain and encouraging patients to exercise comfortably.

This study has some limitations. First, it was not a randomized controlled study. However, designing a randomized controlled study for managing patients experiencing pain is very difficult. We hope that this study will encourage further studies of this type. When designing a randomized controlled study about the effectiveness of ESI for managing LBP, deter- mining a control group is also difficult. An epidural saline injection can have a role in washing out inflammatory cytokines. A comparison between an ESI group and a non-ESI group was impossible for a double-blind study. A comparison between ESI and needling only is difficult because enrolling patients into the control group is thought to be unethical and clinically impractical. Second, long-term follow-up was determined by retrospective chart review and telephone interviews. However, practically, it was difficult to ask patients to revisit the hospital only for the study if they had no pain or discomfort. Third, various possible outcome predictors such as compliance with exercise, smoking, and other life stressors were not evaluated. This is a limitation of the outcome analysis depending on the medical chart. Further study with detailed analysis for various outcome predictors is necessary by prospective design and with larger patient populations.

\section{Conclusions}

In conclusion, the therapeutic trial of a fluoroscopic interlaminar ESI was effective for axial LBP without a significant outcome predictor.

\section{Acknowledgments}

We thank Hye Eun Han and Jung Min Choi for their assistance in telephone interviews and chart review.

\section{References}

1. Manchikanti L. Medicare in interventional pain management: a critical analysis. Pain Physician 2006;9:171-97

2. Manchikanti L, Cash KA, McManus CD, et al. Preliminary results of a randomized, equivalence trial of fluoroscopic caudal epidural injections in managing chronic low back pain. Part 1. Discogenic pain without disc herniation or radiculitis. Pain Physician 2008;11:713-16

3. Friedly J, Chan L, Deyo R. Increases in lumbosacral injections in the Medicare population: 1994 to 2001. Spine (Phila Pa 1976) 2007;32:1754-60

4. Buttermann GR. The effect of spinal steroid injections for degenerative disc disease. Spine J 2004;4:495-505

5. Manchikanti L, Singh V, Rivera JJ, et al. Effectiveness of caudal epidural injections in discogram positive and negative chronic low back pain. Pain Physician 2002;5:18-29

6. Manchikanti L, Pampati V, Rivera JJ, et al. Caudal epidural injections with sarapin or steroids in chronic low back pain. Pain Physician 2001;4:322-35

7. Parr AT, Diwan S, Abdi S. Lumbar interlaminar epidural injections in managing chronic low back and lower extremity pain: a systematic review. Pain Physician 2009;12:163-88

8. Khot A, Bowditch M, Powell J, et al. The use of intradiscal steroid therapy for lumbar spinal discogenic pain: a randomized controlled trial. Spine (Phila $\mathrm{Pa}$ 1976) 2004;29:833-36, discussion 837

9. Hyodo H, Sato T, Sasaki H, et al. Discogenic pain in acute nonspecific low-back pain. Eur Spine J 2005;14:573-77

10. McCarron RF, Wimpee MW, Hudkins PG, et al. The inflammatory effect of nucleus pulposus: a possible element in the pathogenesis of low-back pain. Spine (Phila Pa 1976) 1987;12:760-64

11. Kang JD, Georgescu HI, McIntyre-Larkin L, et al. Herniated lumbar intervertebral discs spontaneously produce matrix metalloproteinases, nitric oxide, interleukin-6, and prostaglandin E2. Spine (Phila Pa 1976) 1996;21:271-77

12. Matsui $Y$, Maeda M, Nakagami W, et al. The involvement of matrix metalloproteinases and inflammation in lumbar disc herniation. Spine (Phila $\mathrm{Pa}$ 1976) 1998;23:863-68, discussion 868-69

13. Virri J, Gronblad M, Seitsalo S, et al. Comparison of the prevalence of inflammatory cells in subtypes of disc herniations and associations with straight leg raising. Spine (Phila Pa 1976) 2001;26:2311-15

14. Fardon DF, Milette PC. Nomenclature and classification of lumbar disc pathology: recommendations of the combined task forces of the North American Spine Society, American Society of Spine Radiology, and American Society of Neuroradiology. Spine (Phila Pa 1976) 2001;26:E93-113

15. Aprill C, Bogduk N. High-intensity zone: a diagnostic sign of painful lumbar disc on magnetic resonance imaging. Br J Radiol 1992;65:361-69

16. Modic MT, Steinberg PM, Ross JS, et al. Degenerative disk disease: assessment 
of changes in vertebral body marrow with MR imaging. Radiology 1988;166: 193-99

17. Barre L, Lutz GE, Southern D, et al. Fluoroscopically guided caudal epidural steroid injections for lumbar spinal stenosis: a retrospective evaluation of long-term efficacy. Pain Physician 2004;7:187-93

18. Manchikanti L, Singh V, Pampati V, et al. Evaluation of the relative contributions of various structures in chronic low back pain. Pain Physician 2001;4: $308-16$

19. Flower RJ, Blackwell GJ. Anti-inflammatory steroids induce biosynthesis of a phospholipase A2 inhibitor which prevents prostaglandin generation. Nature 1979;278:456-59

20. Manchikanti L. Role of neuraxial steroids in interventional pain management. Pain Physician 2002;5:182-99

21. Wolfer LR, Derby R, Lee JE, et al. Systematic review of lumbar provocation discography in asymptomatic subjects with a meta-analysis of false-positive rates. Pain Physician 2008;11:513-38

22. Carragee EJ, Lincoln T, Parmar VS, et al. A gold standard evaluation of the "discogenic pain" diagnosis as determined by provocative discography. Spine (Phila Pa 1976) 2006;31:2115-23

23. Manchikanti L, Glaser SE, Wolfer L, et al. Systematic review of lumbar discography as a diagnostic test for chronic low back pain. Pain Physician 2009; 12:541-59

24. Carragee EJ, Alamin TF, Carragee JM. Low-pressure positive discography in subjects asymptomatic of significant low back pain illness. Spine (Phila $\mathrm{Pa}$ 1976) 2006;31:505-09

25. Boswell MV, Trescot AM, Datta S, et al. Interventional techniques: evidencebased practice guidelines in the management of chronic spinal pain. Pain Physician 2007;10:7-111 